\title{
Free convection on a refrigerator's condenser
}

\author{
T. Orzechowski ${ }^{1, a}$, K. Stokowiec ${ }^{1}$ \\ ${ }^{1}$ Kielce University of Technology, Environmental Engineering Dep., Heat Engineering Div. Kielce, Poland
}

\begin{abstract}
The paper presents the measurement of heat transfer coefficient for the refrigerator's condenser in free convection regime. The water was pumped through the steel coils of heat exchanger with a constant flow rate and its temperature was kept at a demanded value by means of ultrathermostat. The research was conducted in stationary conditions which were controlled by a continuous measurement of the water temperature at inflow and outflow to the heat exchanger. The temperature distribution at the external condenser surface was registered by means of an infrared camera. Single elements used to the analysis were selected using the thermogram registered. In free convection regime and in case of small temperature change the heat transfer coefficient value can be calculated by comparing the measured temperature area with analytical solution describing one-dimensional temperature distribution along the rib. The accuracy of the proposed method for measuring the heat transfer coefficient was examined by comparing the heat transferred to the air and the heat lost by water flowing through the spiral of heat exchanger. An error between these two parameters is about $6 \%$.
\end{abstract}

\section{Introduction}

Heat exchangers, which are one of the most popular devices for the heat transfer, are often used in engineering practice, both in industrial and residential applications. They are commonly used not only in the heating and ventilating or cooling process, but also in food or pharmaceutical industry, shipbuilding as well as chemical and petrochemical machinery. They have been well known for hundred years, but due to the continuous development of new technologies constant effort on the optimization of their operation is involved. Therefore, it is an important issue to limit the heat transfer surface by reducing the size and weight of heat exchangers, without decreasing their performance while improving the efficiency of their operation. This is essential for processes which aim is to reduce energy consumption in both conventional and renewable systems. An additional advantage is the reduction of greenhouse gas emission that comes from the use of fossil fuels.

The wide range of heat exchangers applications is visible in the variety of their types. They can be divided by its design, the sort of heat transfer fluid or the heat exchanger setup (co-flow, counter-flow and cross-flow). Taking into consideration the first category, we can name plate, spiral, lamellar, capacitive, shell and tube, heat pipe, or "pipe in pipe" heat exchangers. The variety of possible engineering solutions depending on the type of applications require individual calculations, including the performance optimization.
In order to improve the heat transfer process in heat exchangers, it is possible to use both active and passive methods. In active systems, additional force is needed to receive the desired effect while in passive ones geometry is changed in order to increase the heat transfer coefficient $[1,2]$. Additionally, the heat transfer surfaces of twisted tape spiral wires, bars and pin elements are used for required surface extention [3].

Heat exchangers are also used in energy recovery from industrial processes. Mathematical modelling was developed for identifying the most suitable type of exchanger, its surface and heat gains $[4,5,6]$ for those requirements. Not only an estimation of coefficient of performance, but also financial benefits of such solutions were calculated.

The experiments on heat exchangers involve processes using phase change materials. They can be used as a heat store by melting processes. After conducting the tests, it was estimated that the Reynolds number at turbulent flow through the heat exchanger is beneficial when we need faster phase change as well as the reduction of phase change process time by half is necessary [7]. However, for such solutions suitable are tube heat exchangers with a phase-change material set in a matrix of graphite or finned tube heat exchangers.

Condensers commonly used in refrigerators are, among other types of heat exchangers, widely investigated by the researchers. We obtain mathematical models, that use the theory of thermodynamics, in order to optimize the operation in refrigerators and receive the

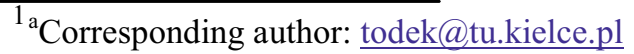


highest possible coefficient of performance at the same time [8]. However, the experiments involve heat transfer characteristics by using the insulating wall and the transferred heat loss method on performing refrigerators [9]. The literature presents several experimental studies on real systems with chillers containing different refrigerants [10], where the mathematical models are developed and solved numerically. The necessary heat transfer coefficients are usually based on the correlations reported in the literature. In the forced convection conditions and basing on the second law of thermodynamics, a method of higher efficiency condenser at a lower temperature distribution difference between the hot and cold fluid in the heat exchanger has been discussed in [11]. The most commonly considered type is a heat exchanger arranged in a serpentine shape with cross ribs welded in order to increase the heat transfer rate. An important issue of such systems is to determine the amount of ribs employed in wet regime and hence the heat transfer rate due to condensation. It has been estimated that it may exceed 10 times the value of heat transfer coefficient [12]. However, the number of tubes has a negligible effect on the efficiency of the heat exchanger [13], but important issue is the distance between the cross located ribs in the heat exchanger, which should be increased [14]. However, a properly selected system affects not only the heat transfer process with the ambient, but also the efficiency of the refrigerators. The negative effect of the air presence in the condenser on the condensation process of the refrigeration medium proves a decrease in the heat transfer coefficient, enlargement of the condensation zone, and an increase in the flow resistance in the multiphase multi-component flow system [15]. Another issue seems to be the influence of hydrodynamic instabilities on heat transfer intensity during the condensation of refrigerants [16].

Chillers condensers are tested not only when located directly on the fridge or in ambient air, but also with phase change material cooperation [7].

The phenomenon known as the zero boiling crisis and the influence of the flashing phenomenon on the boiling curve show the importance of these elements on heat transfer in single- and two-phase systems where condensers are applied [17].

For proper design and selection of refrigerator condenser it is necessary to know the heat transfer coefficients on both the condensing refrigerant side, as well as from the heat transfer medium side, which is usually the ambient air. Condensers are constructed with the repeating elements of the same geometry. These are usually rib elements fixed at the base of the tube where the liquid refrigerant condenses. Such a design allows the modeling of a system basing on repetitive elements, for which, the amount of dissipated heat needs to be estimated. The aim of this paper is to provide a fast and effective method of measuring the heat transfer coefficient on the example of a typical refrigerator condenser.

\section{Test facility}

This paper concerns the measurement of heat transfer coefficient for the condenser cooler under natural convection at quiescent atmosphere. A siplified test facility diagram is presented in figure 1 .

The condenser is made of steel. Water at constant volume rate flows through the exchanger coils, which desired temperature was maintained by means of ultrathermostat. The study was conducted in stationary conditions, which were controlled by continuous measurement of the temperature at the inlet and outlet of the heat exchanger. Three thermocouples were applied for this purpose. Two of them were located at the coil inlet and outlet respectively, and the third one was used

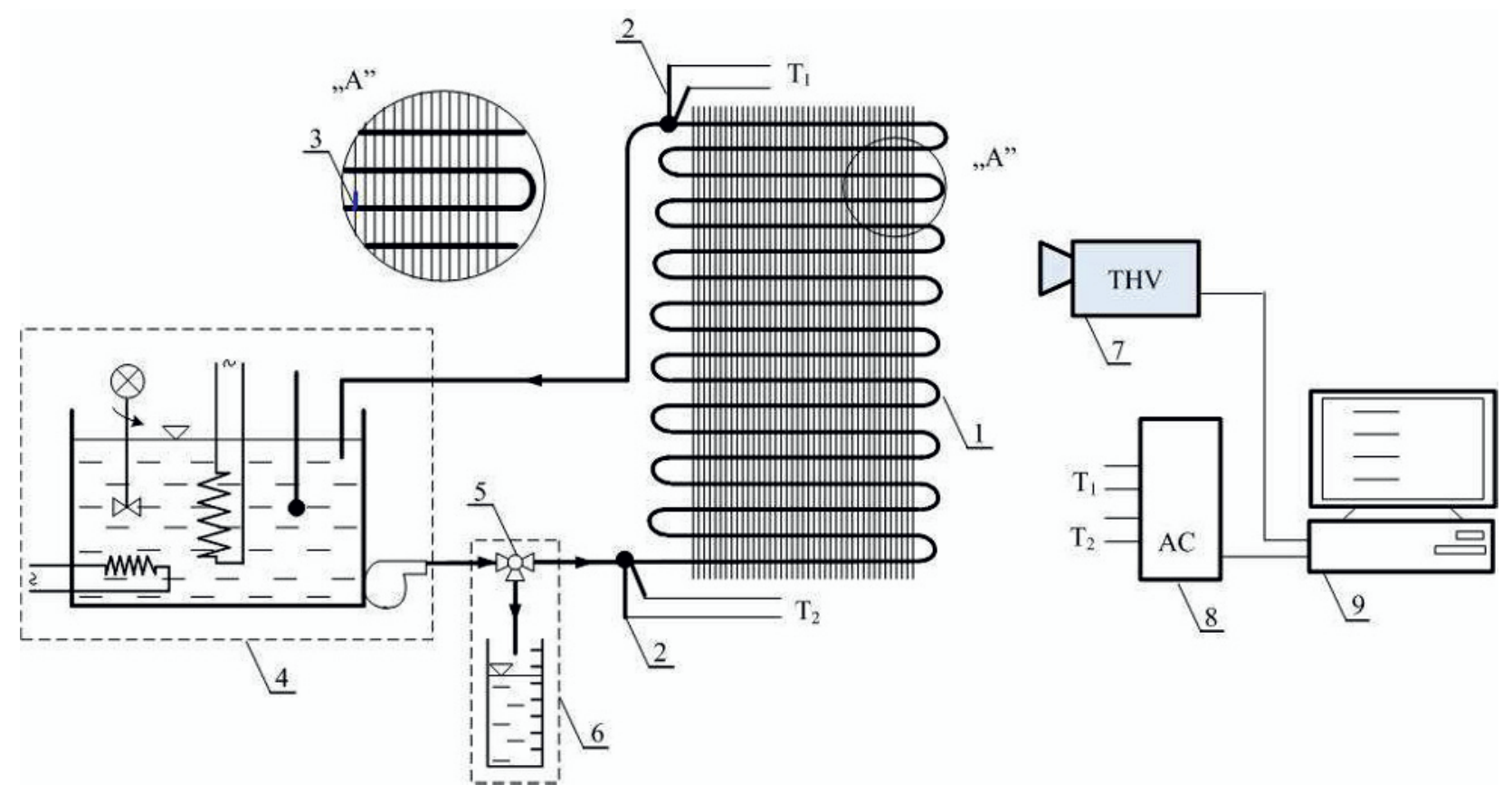

Figure 1. Test facility diagram

1 - heat exchanger, 2 - thermocouple, 3 - single rib, 4 - ultrathermostat, 5 - three-way valve, 6 - system to mass flow rate measurement, 7 - infrared camera, 8 - data acquisition station with AC cards, 9 - computer 
to record the ambient temperature throughout the experiment. In addition, the temperature in ultrathermostat was controlled. All data were recorded using a data acquisition station DaqLab, which is equipped with a thermocouple card. The temperature distribution on the outer surface of the condenser was recorded by means of infrared camera VarioCAM ${ }^{\circledR} \mathrm{hr}$ head of Jenoptik. The camera works in a long-term infrared range between $7.5 \div 14 \mu \mathrm{m}$. An element that converts part of an infra-red radiation sent by the body into an electrical signal is microbolometer array with a resolution of $640 \times 480$ pixels. To get the proper temperature recorded by THV-camera, calibration studies were conducted to determine the emissivity, which allows the exact temperature setting [18].

\section{Methodology}

Amount of water flowing through the exchanger was determined by measuring its volume and time. In order to do this, water flowing into the heat exchanger was interrupted by using the three-way valve. It was a method to calculate a volume flow rate.

The result of tests with the infrared camera is the temperature distribution on the outer surface of the heat exchanger. Single elements that link adjoining sections arranged in a serpentine shape pipe with water were selected using the registered thermal image. For those elements the temperature distribution was analyzed and the heat transfer coefficient was determined. An example of the temperature distribution is shown in Figure 2.

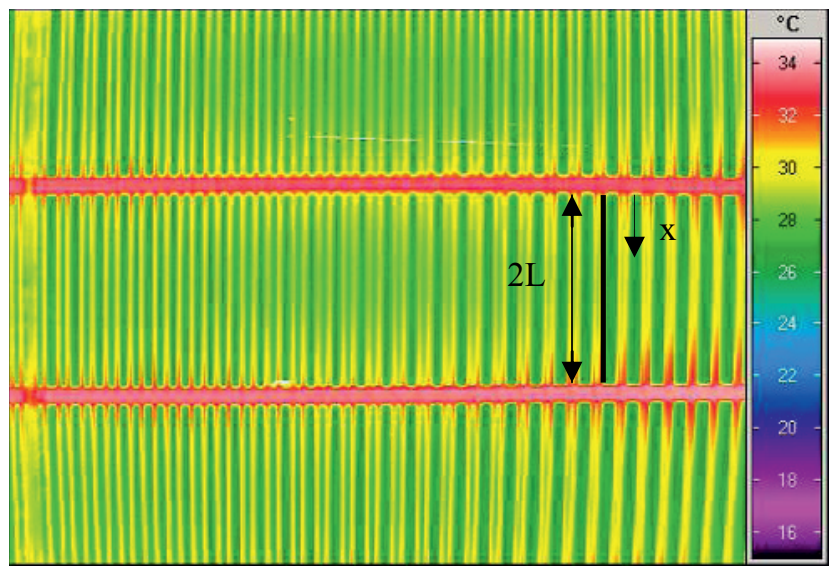

Figure 2. Thermogram of a condenser

The temperature distribution on the repetitive element connecting the adjoining coil pipes is shown in Figure 3. Such a structure works as a system of two ribs connected with frontal surfaces.

In natural convection regime and small temperature range the heat transfer coefficient is nearly constant [19]. Its value can be determined by comparing the measured temperature field with one-dimensional solution describing the temperature distribution along the rib. In that case, the studied element is divided into two parts so that the temperature derivative at their ends equals zero, which represnts the problem of an isolated rib at an end. For those assumptions, in case of heat conduction in the

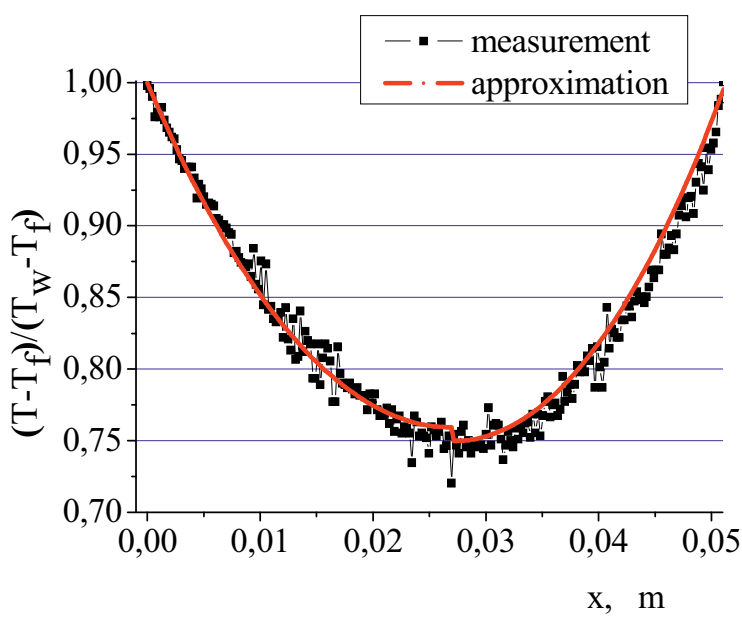

Figure 3. Temperature distribution along the rib

steady state with no internal heat sources, the formula for heat transfer in the rib with constant cross-section is:

$$
T-T_{f}=\left(T_{w}-T_{f}\right)\left(\frac{e^{m x}}{1+e^{2 m L}}+\frac{e^{-m x}}{1+e^{-2 m L}}\right)
$$

where: $T_{w}$ temperature at the base of the rib, ${ }^{\circ} \mathrm{C}, T$ current temperature, ${ }^{\circ} \mathrm{C}, T_{f}$ ambient temperature, ${ }^{\circ} \mathrm{C}, L$ rib length, $\mathrm{m}, m^{2}=\alpha P /(\lambda F), x$ coordinate along the rib, $\mathrm{m}, \alpha$ heat transfer coefficient, $\mathrm{W} \mathrm{m} \mathrm{m}^{-2} \mathrm{~K}^{-1}, P$ element perimeter, $\mathrm{m}$, $\lambda$ heat conduction coefficient, $\mathrm{W} \mathrm{m}^{-1} \mathrm{~K}^{-1}, F$ cross section area, $\mathrm{m}^{2}$

Using the function (1) an estimation of the measured data can be done. The calculation was performed with a minimum mean square error assumption. The obtained function of the experimental data with a constant coefficient of heat transfer presents the good quality match (see figure 3). Difference in the temperature measured and fitted is shown in figure 4. For the presented set the standard deviation is $0.095^{\circ} \mathrm{C}$. That value is in the range of the sensitivity of the infrared camera, which for equipment used is $\sim 0.08 \mathrm{~K}$.

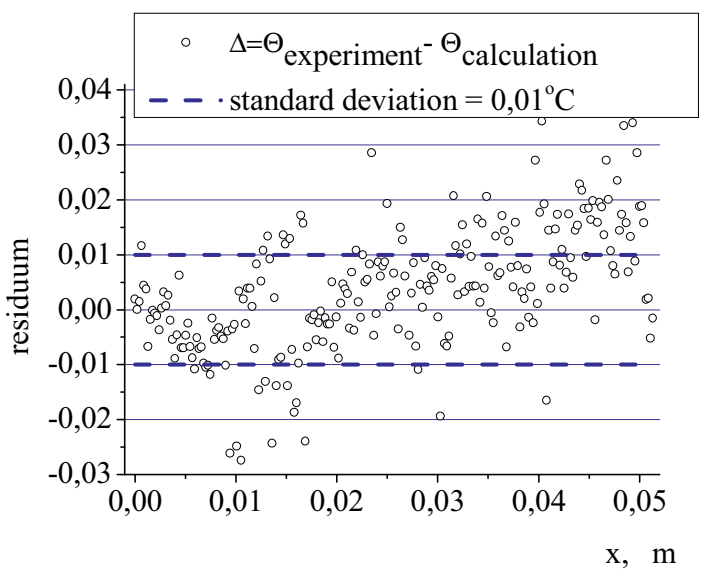

Figure 4. Residuum from the data in Figure 3. 
Using the formula (1) we can calculate $q$ the rate of heat loss to the environment from a single rib, which is given by the formula (2)

$$
q=\sqrt{\alpha P \lambda F} \cdot\left(T_{w i}-T_{f}\right) \cdot \tanh \left(\sqrt{\frac{\alpha P}{\lambda F}} \cdot L\right)
$$

where: $\alpha$ heat transfer coefficient, $\mathrm{W} \mathrm{m}^{-2} \mathrm{~K}^{-1}, P$ element perimeter, $\mathrm{m}, \lambda$ heat conduction coefficient, $\mathrm{W} \mathrm{m} \mathrm{m}^{-1} \mathrm{~K}^{-1}$, $F$ cross section area, $\mathrm{m}^{2}, L-$ rib length, $\mathrm{m}$

The heat transfer coefficients were calculated using the experimental data approximation with function (1) as shown in figure 3 . The calculated values for the presented data are $13.1 \mathrm{~W} \mathrm{~m}^{-2} \mathrm{~K}^{-1}$ for an upper rib and $17.8 \mathrm{~W} \mathrm{~m}^{-2} \mathrm{~K}^{-1}$ for a lower rib. Applying the same procedure, the heat transfer coefficients were calculated for all the condenser elements. Their values do not show any significant changes. The average value of heat transfer coefficient for the condenser is $17 \mathrm{~W} \mathrm{~m}^{-2} \mathrm{~K}^{-1}$ for an upper rib and $18.2 \mathrm{~W} \mathrm{~m}^{-2} \mathrm{~K}^{-1}$ for a lower rib. Loss of heat rate dissipated by a single rib is calculated according to equation with the measured heat transfer coefficients (2). Its value for the presented rib is $0.016 \mathrm{~W}$.

An analyzed element is welded to the water pipe, which temperature gradually decreases along its length, with the result that the temperature at both ends of a single rib is different. The measurement is conducted under stationary conditions at a predetermined water flow and at constant ambient temperature. The result is a constant temperature difference of water at the inlet and outlet of the heat exchanger, which is $\sim 5 \mathrm{~K}$. Its distribution in the different points along the ribs can be read from the thermograph and its sample distribution along the length of condenser in the direction of water flow is shown in figure 5 . Due to the small difference between the temperatures at the inlet and outlet and the relatively large length of the coils, the temperatures can be approximated by a straight line with a good estimation. It is worth noting, that for the studies presented, the exponential function approximation coincides with the given line.

The quality of approximation was assessed calculating the standard deviation in each case and for the data in figure 3 its value is $0.8^{\mathrm{O}} \mathrm{C}$.

The temperature drop of water flowing through the condenser coil, corresponds to a decrease of temperature on the length of the condenser. To calculate the heat loss through the coil, in which water flows, the following relation for Nusselt number given by Churchill and Chu was used [19]:

$$
N u=\left\{0.6+\frac{0.387 R a^{1 / 6}}{\left.\left[1+(0.559 / \mathrm{Pr})^{9 / 16}\right]\right]^{8 / 27}}\right\}^{2}
$$

where: $R a$ Rayleigh number, $\operatorname{Pr}$ Prandtl number

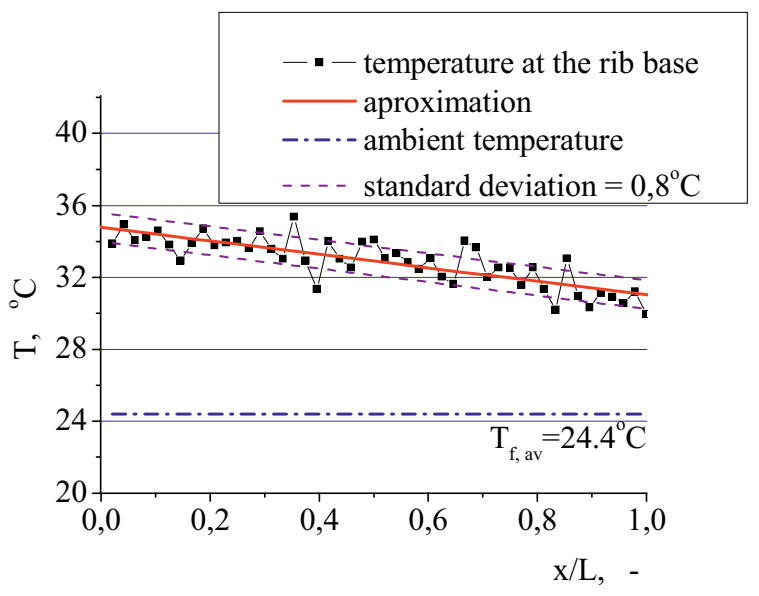

Figure 5. The temperature decrease at the rib base along the condenser coils length

Using equation (3) heat transfer coefficient was calculated for horizontally arranged pipe with fluid flowing with an average temperature $(\mathrm{T} 1+\mathrm{T} 2) / 2$. It was applied to calculate the heat dissipated by the condenser coil, which is $26.4 \mathrm{~W}$. After summing up the calculated values for each heat exchanger ribs, the dissipated heat is $28.4 \mathrm{~W}$, likewise. The condenser performance calculated with this method is $54.8 \mathrm{~W}$ and it is slightly lower than the capacity resulting from the temperature decrease in flowing water (the difference is $\sim 3.7 \mathrm{~W}$ ). This happens due to measurement errors as well as different to model conditions operation of the whole system. The nature of the cooling air flow around the condenser is very complex and is also a source of discrepancy in the heat balance received by the air and lost by water.

\section{Conclusions}

The paper presents the measurement of heat transfer coefficient for the refrigerator's condenser in free convection regime. In order to improve the heat transfer, we chose an exchanger with cross steel ribs. The measurement was conducted in stationary conditions with a constant water flow rate. Temperature distribution on the outer surface of the heat exchanger was measured using an infrared camera.

Basing on the thermogram for a single rib and temperature read from it, we calculated $m$ the temperature coefficient of the rib. The method allowed to estimate the heat-transfer coefficient. The approximation presents a very good match proved by low standard deviations. It makes the mathematical model possible to be be adopted to determine the heat transfer coefficients for similar exchangers. Exceptions result from an industrial welding of individual elements.

In the paper the heat dissipated to the ambient by the condenser coils and cross ribs as well as the heat flux transferred to the condenser by flowing water were calculated. The difference in both values is low (absolute error do not exceed 6\%), which means that the assumed method was suitable. 


\section{References}

[1] W.M. Rosenhow, J.P. Hartnett, E.N. Ganic, Handbook of Heat Transfer Applications (McGraw-Hill, New York, 1985)

[2] A.E. Bergles, Heat Transfer Enhancement of Heat Exchangers (Kluwer Academic Publishers, Dordrecht, 1998)

[3] N. Sahiti, F. Durst, A. Dewan, Int J Heat Mass Tran 48 4738-4747 (2005)

[4] I. Teke, Ö. Agra, Ö. Atayılmaz, H. Demir, Appl Therm Eng 30 577-583 (2010)

[5] M.S. Soylemez, Energ Convers Manage 41 14191427 (2000)

[6] Ö. Agra, Appl Therm Eng 31 727-734 (2011)

[7] M. Medrano, M.O. Yilmaz, M. Nogués, I. Martorell, Joan Roca, Luisa F. Cabeza, Appl Energ 86 2047-2055 (2009)

[8] J. Luo, L. Chen, F. Sun, Ch. Wu, Energ Convers Manage 44 3197-3206 (2003)

[9] J. S. Sim, J. S. Ha, Int Commun Heat Mass 38572 $576(2011)$

[10] P.K. Bansal, T.C. Chin, Appl Therm Eng 22 16011617 (2002)

[11] Z-Y. Guo, S-Q. Zhou, Z-X. Li, L-G. Chen, , Int J Heat Mass Tran 45 2119-2127 (2002)

[12] C. Bougriou, R. Bessa1“h, Appl Therm Eng 25 1863-1870 (2005)

[13] J-Y. San, G-S. Lin, K-L. Pai, Appl Therm Eng 29 3081-3087 (2009)

[14] Y. Kim, Int. J. of Refrigeration 28 851-858 (2005)

[15] T. Bohdal , R. Matysko Appl Therm Eng 26 19421950 (2006)

[16] W. Kuczyński, H. Charun, T. Bohdal, Int J Heat Mass Tran 55 1083-1094 (2012)

[17] K. Dutkowski. , Int J Heat Mass Tran 53 1036-1043 (2010)

[18] T. Kruczek, W. Adamczyk, R.A. Białecki, Int. J. of Thermophys. 34, 3 (2013)

[19] F. Incropera, D. Dewitt, T. Bergman, A. Lavine, Fundamentals of Heat and Mass Transfer, (2006) 